\title{
The prevalence and types of coronary artery abnormalities in pediatric patients with Tetralogy of Fallot
}

Nima Mehdizadegan

Shiraz Medical School: Shiraz University of Medical Sciences

Kholud Saeidi

Shiraz Medical School: Shiraz University of Medical Sciences

Kambiz Keshavarz ( $\sim$ kmbz_ped86@yahoo.com)

Yasuj University of Medical Sciences https://orcid.org/0000-0002-9728-4112

\section{Research}

Keywords: TOF, extreme caudal, LAO cranial , selective coronary, RVOT

Posted Date: January 25th, 2021

DOl: https://doi.org/10.21203/rs.3.rs-153158/v1

License: (c) (i) This work is licensed under a Creative Commons Attribution 4.0 International License.

Read Full License 


\section{Abstract}

Objectives:

Tetralogy of fallot (TOF) is one of the most common diseases among cyanotic congenital heart diseases which is associated with $2-23 \%$ of coronary artery abnormalities. Pre-operation knowledge the anatomy of coronary arteries in patients with TOF eliminates damage to them during surgery and prevents postoperative complications such as myocardial ischemia and heart failure.

Materials and methods:

This retrospective study was done on all patients with TOF who were referred for diagnostic catheterization and angiography before total surgical correction from 2006-2016. All patients entered the study and all angiographic views including extreme caudal, LAO cranial , and selective coronary artery angiography were evaluated and reviewed accurately.

Results:

332 cases of patients with TOF including from one month to 36 years old were reviewed. The prevalence of coronary artery abnormalities among them was $11.4 \%$ (38 from 322 individual). $9.1 \%$ and $15.3 \%$ of males and females had abnormal coronary anomalies but it was not significant statically ( $p$-value: 0.064). In 13 of 38 patients with coronary anomalies, coronary arteries crossed right ventricular out flow tract (RVOT)(3.4\%). The most common coronary abnormality was origin of the both main coronary arteries from left sinus of Valsalva.

Conclusion:

Compared with other populations, the abnormal arteries among the patients with TOF in our study is significant (11.4\%) and accurate assessment of their courses is necessary before surgery. Single origin of coronary arteries from the left side was the most common finding in our study too.

\section{Introduction:}

Congenital heart disease is the most common Congenital defect in newborns (1). Coronary artery anomalies (CAA) are common in many congenital heart diseases (2) such as those that cross the entire face of ventricular infundibulum superficially in patients with tetralogy of Fallot (TOF) (3).

According to different studies based on diagnostic angiography, surgery and atopies the prevalence of coronary abnormalities vary from $2-14 \%$ to $2-23 \%(1,4)$.

Based on one metanalysis study on the patients with TOF, the most anomalous coronary arteries were those that crossing the RVOT, large conus artery , crossing behind the aorta, coronary arteriovenous fistula , left or right coronary artery from the pulmonary trunk or left or right pulmonary artery , coronary 
tree hypoplasia and anastomoses between coronary and branchial arteries. The combined risk of encountering an anomalous coronary artery or a large conus artery crossing the RVOT was reported $10.3 \%(5)$.

Knowing the origin and course of coronary arteries is essential for surgeon before starting the operation.

Today in most centers the coronary anatomy is delineated by echocardiography. Rarely in patients with TOF, heart catheterization is used as primary indication to study of coronary pattern (6).

Because of the several types of coronary anomalies in the patients with TOF, this study was done for another investigation of these anomalies in TOF before corrective surgery.

\section{Methods:}

This retrospective study was carried on all patients whit TOF who were referred for diagnostic cardiac catheterization and angiography before total surgical correction in 2006-2016.

All patients entered the study and all angiographic views including extreme caudal, LAO cranial and in some cases, selective coronary artery views were evaluated accurately .

\section{Results:}

The records of 322 patients with TOF were reviewed. The patients including 318 children and 18 adults were between 1 month to 36 years old(table No. 1). Of 322 patients, 208 were male (62.65\%) and 124 were female (37.35\%). 
Table No.1: patients and age

\begin{tabular}{|c|c|c|c|c|c|}
\hline & & Frequency & Percent & Valid Percent & Cumulative Percent \\
\hline \multirow[t]{27}{*}{ Valid } & 1month & 23 & 6.0 & 6.0 & 6.0 \\
\hline & 2 month & 4 & 1.0 & 1.0 & 8.0 \\
\hline & 3month & 5 & 1.0 & 1.0 & 9.0 \\
\hline & 4month & 1 & .0 & .0 & 9.0 \\
\hline & 5month & 12 & 3.0 & 3.0 & 13.0 \\
\hline & 6 month & 11 & 3.0 & 3.0 & 16.0 \\
\hline & 7month & 20 & 6.0 & 6.0 & 22.0 \\
\hline & 8month & 27 & 8.0 & 8.0 & 31.0 \\
\hline & 9month & 22 & 6.0 & 6.0 & 37.0 \\
\hline & 10month & 16 & 4.0 & 4.0 & 42.0 \\
\hline & 11 month & 19 & 5.0 & 5.0 & 48.0 \\
\hline & 12 month & 23 & 6.0 & 6.0 & 55.0 \\
\hline & 13 month & 3 & .0 & .0 & 56.0 \\
\hline & 14 month & 5 & 1.0 & 1.0 & 57.0 \\
\hline & 15 month & 2 & .0 & .0 & 58.0 \\
\hline & 16 month & 2 & .0 & .0 & 58.0 \\
\hline & 17month & 8 & 2.0 & 2.0 & 61.0 \\
\hline & 18month & 2 & .0 & .0 & 61.0 \\
\hline & 19month & 4 & 1.0 & 1.0 & 62.0 \\
\hline & 20 month & 2 & .0 & .0 & 63.0 \\
\hline & 21 month & 2 & .0 & .0 & 64.0 \\
\hline & 22 month & 1 & .0 & .0 & 64.0 \\
\hline & 23month & 1 & .0 & .0 & 64.0 \\
\hline & 2 years & 28 & 8.0 & 8.0 & 73.0 \\
\hline & 3years & 15 & 4.0 & 4.0 & 77.0 \\
\hline & 4years & 6 & 1.0 & 1.0 & 79.0 \\
\hline & 5years & 10 & 3.0 & 3.0 & 82.0 \\
\hline
\end{tabular}




\begin{tabular}{|lllll|}
\hline 6years & 3 & .0 & .0 & 83.0 \\
\hline 7years & 6 & 1.0 & 1.0 & 85.0 \\
\hline 8years & 4 & 1.0 & 1.0 & 86.0 \\
\hline 9years & 6 & 1.0 & 1.0 & 88.0 \\
\hline 10years & 2 & .0 & .0 & 88.0 \\
\hline 11years & 2 & .0 & .0 & 89.0 \\
\hline 12years & 2 & .0 & .0 & 90.1 \\
\hline 13years & 1 & .0 & .0 & 90.0 \\
\hline 15years & 7 & 2.0 & 2.0 & 92.0 \\
\hline 16years & 3 & .0 & .0 & 93.0 \\
\hline 17years & 2 & .0 & .0 & 93.0 \\
\hline 18years & 6 & 1.0 & 1.0 & 95.0 \\
\hline 19years & 3 & .0 & .0 & 96.0 \\
\hline 21years & 1 & .0 & .0 & 96.0 \\
\hline 22years & 2 & .0 & .0 & 97.0 \\
\hline 23years & 2 & .0 & .0 & 98.0 \\
\hline 26years & 2 & .0 & .0 & 98.0 \\
\hline 31years & 2 & .0 & .0 & 99.0 \\
\hline 32years & 1 & .0 & .0 & .0 \\
\hline 36years & 1 & .0 & 100.0 & \\
\hline Total & 332 & 100.0 & .0 & \\
\hline & & .0 & .0 \\
\hline
\end{tabular}

Coronary artery abnormalities were found in 38 patients totally(11.4\%), 9.1\% and $15.3 \%$ in males and females respectively (table No.2).

Table No.2: Prevalence of coronary abnormalities in patients with TOF 


\begin{tabular}{|llll|}
\hline Gender & Normal & Abnormal & Total \\
\hline Male & 189 & 19 & 208 \\
& $(90.9 \%)$ & $(9.1 \%)$ & $(100.0 \%)$ \\
\hline Female & 105 & 19 & 124 \\
& $(84.7 \%)$ & $(15.3 \%)$ & $(100.0 \%)$ \\
Total & 246 & 38 & 332 \\
& $(88.6 \%)$ & $(11.4 \%)$ & $(100.0 \%)$ \\
\hline
\end{tabular}

Despite the apparent difference between the percentages of coronary abnormalities in two genders, the Pvalue was not significance $(P$-value $=0.064)$.

Abnormal coronary arteries were found in 38 patients (11.4\%).

Coronary arteries crossing RVOT, RCA and LCA originated from LCC and RCC respectively, and single origin of coronary arteries from left side without crossing the RVOT were the most common abnormalities that found in 13,1 and 24 patients respectively.

Among them with coronary arteries crossing RVOT(13 of $38(34 \%))$ several varieties were detected; single origin of coronary arteries from left side accompany with LAD passed over the RVOT, single origin of coronary arteries from left side accompany with RCA passed over the RVOT , single origin of coronary arteries from left side accompany with both RCA and LCA passed over RVOT, and also single origin of coronary arteries from right side accompany with LAD passed over the RVOT were found in 3, 2, 2, and 4 patients respectively. In one patient with single origin of coronary arteries from left side LCA passed RVOT.

Despite the normal course of coronary arteries, passing the both RCA and LAD was detected in one patient. (table.3).

Table:3: prevalence and types of coronary artery anomalies : 


\begin{tabular}{|c|c|c|c|c|}
\hline & Frequency & percent & $\begin{array}{l}\text { Valid } \\
\text { percent }\end{array}$ & $\begin{array}{l}\text { Cumulative } \\
\text { percent }\end{array}$ \\
\hline Normal & 246 & 88 & 88 & 88 \\
\hline Single origin from left side (SOFLS) & 24 & 7 & 7 & 45 \\
\hline $\begin{array}{l}\text { Single origin from left side (SOFLS) } \\
+ \text { LAD Passing RVOT }\end{array}$ & 3 & .0 & .0 & 46 \\
\hline SOFLS+ RCA passing RVOT & 2 & .0 & .0 & 47 \\
\hline RCA from LCC and LCA from RCC & 1 & .0 & .0 & 47 \\
\hline SOFLS+ RCA and LCA passing RVOT & 2 & .0 & .0 & 98 \\
\hline RCA and LAD passing RVOT & 1 & .0 & .0 & 98 \\
\hline SOFLS + LAD passing RVOT & 4 & 1.0 & 1.0 & 99 \\
\hline SOFLS+ LCA passing RVOT & 1 & .0 & .0 & 100 \\
\hline Total & 332 & 100 & 100 & \\
\hline
\end{tabular}

\section{Discussion:}

Having knowledge about abnormalities of coronary arteries in patients with TOF is an important key to avoid them getting damage during surgical correction (4-11-12).

Damaging coronary arteries may led to hemi block conduction in patients with dominate right sided coronary circulation or post-operative myocardial infarction (9). As such coronary anomalies may not be seen during operation because of epicardia fat and their position, this pre-operative recognition helps surgeons to get the best strategies before and during surgical correction in patients with TOF.

Although today in most centers the coronary anatomy is delineated by echocardiography, angiography is used as an accurate method before this purpose yet $(6,2,10,13,14)$.

The prevalence of coronary anomalies in paints with TOF was reported in 77 of 607(12\%) individual with TOF or TOF like anatomy(14). The other reports by Shirvastava and et al(10), Dabizzi et al(7), Hekmati et al (18), Farsani et al (16) and Gupta et al (17) on similar patients, showed the same prevalence of coronary anomalies among the patients with $\operatorname{TOF}(11.4 \%)$. In our study, the prevalence of anomalous coronary arteries crossing the RVOT was 3.4\% (13 from 38 individuals among the patients with TOF and abnormal coronary artery ) which was lower than the Turkish population (14). 
Distribution rate of coronary anomalies based on the sex in our study was similar with Turkish population (66.2\% male and $33.8 \%$ female in Turkish study (14) versus $62.65 \%$ male and $37.35 \%$ in our study).

The most coronary artery anomaly which reported by Gupta et al, Dabizzi et al, Humes et al, Li et al, Ruzmetov et al, was anomalous origin of $\operatorname{LAD}$ form $\operatorname{RCA}(17,15,18,19,20$ respectively). In our study, single origin of coronary arteries from left side (about $84 \%$ of coronary anomalies and $9.6 \%$ of all involved individuals) was the most common coronary abnormalities in patients with TOF .

\section{Conclusion:}

The prevalence of coronary artery abnormalities among the patients with TOF is significant and in order to eliminate damage to coronary arteries during surgical correction, an accurate evaluation of their courses before operation is inevitable.

In our population it seems this prevalence is at the upper range of worldwide references $(11.4 \%$ versus 2$12 \%$ reported in references). Having knowledge about abnormalities of coronary arteries in these patients helps to surgeons to draw a best strategy before operation.

\section{Declarations}

\section{Acknowledgments}

We would like to thank Miss Sobhani for her helpful collaboration in data collection. The authors would like to thank the Shiraz University of Medical Sciences, Shiraz, Iran, and also Center for Development of Clinical Research of Nemazee Hospital and Mr. H.Argasi at the Research Consultation Center for his invaluable assistance in editing this manuscript.

\section{Authors' contributions}

N.M: design and analysis and manuscript preparation. K.S: Sample collection and data preparation, manuscript preparation. K.K : Design, analysis, statistics and manuscript preparation. All authors read and approved the final manuscript.

\section{Funding}

This article was funded by Shiraz University of Medical Sciences. All of the Catheterization and angiographic evaluations were performed in this university. The funder had no impact on study design, analysis, or result interpretation.

\section{Availability of data and materials}

We state that the data used and/or analyzed during the current study are available from the corresponding author on reasonable request. Data sharing is applicable to this article and datasets were 
generated and analyzed during the current study and data sharing is allowed.

\section{Ethics approval and consent to participate}

All procedures performed in this study were in accordance with the ethical standards of the "Research Ethics Committee of Shiraz University of Medical Sciences" and with the 1964 Helsinki declaration and its later amendments or comparable ethical standards. This study was submitted to and approved by the "Research Ethics Committee of Shiraz University of Medical Sciences".

\section{Consent for publication}

This manuscript does not contain any personal data, and the consent for publication is applicable.

\section{Competing interests}

The authors declare that they have no competing interests.

\section{Author details}

1Cardiovascular Research Center, Department of Pediatrics, School of medicine, Shiraz University of Medical Sciences, Shiraz, Iran. 2Department of Pediatrics, , Shiraz University of Medical Sciences, Shiraz, Iran. 3Social Determinants of Health Research Center, Yasuj University of Medical Sciences, Cardiovascular Research Center, Shiraz University of Medical Sciences

\section{References}

1. Claire J. Koppel- coronary anomalies in TOF-A meta-analysis international Journal of cardiology $0.306-2020$ May $-78-85$.

2. Raffaele Giordano, Massimiliano Continotti , Surgical strategy for TOF abnormal coronary arteries, J Thora Dis. 2017 Oct; 9(10) :3447-3449.

3. Siwik ES, Patel CR, Zahak KG, TOF in: Allen HD, Gutgesell P, Moss and Adam's heart disease in infants, children, and adolescents: Including the fetus and young adult( $9^{\text {th }}$ edition). PhiladelphiaLippincott Williams and Wilkins 2016.

4. Mohamed Rida Ajaja, Amine Cheikh , prevalence and management of coronary artery anomalies in TOF at Cheikh Zaid Hospital's Pediatric Cardiac Surgery Department in Morocco: retrospective study, the pan African Medical Journal , 2019 Nov., 34:157.

5. Claire Koppel, Monique Jongbloed, Philippine Kies, Coronary anomalies in TOF-A meta- analysis, international journal of cardiology, 2020 Feb., 306.

6. Need LR, Powell AJ, del Nido P., Coronary echocardiography in TOF: diagnostic accuracy, resource utilization and surgical implication over 13 years. J Am Coll Cardio 2000, 36:1371-7.

7. Dabizzi RP, Caprioli G, Aiazzi L, Castelli C, Baldright G, Parenzan L, et al. Distribution and anomalies of coronary arteries in tetralogy of fallot, Circulation. 1980;61(1):95-102. 
8. Berry BE, Mc Goon DC, Total correction for tetralogy of Fallot with anomalous coronary artery. Surgery. 1973;74(6):894-8.

9. Carvalho JS, Silva CM, Rigby ML, Shinebourne EA. Angiographic diagnosis of anomalous coronary artery in tetralogy of Fallot, Br Heart J. 1993; 70(1):75-8.

10. Shrivastava S, Mohan JC, Mukhopadhyay S, Radon R. Coronary artery anomalies interalogy of Fallot. Cardiovasc intervent Radiol. 1987; 10(4):215-8.

11. Hussain I, Patel N Ghaffar A. Kundi A. Coronary anomalies in Pakitani children with tetralogy of Fallot . J Coll Physicians Surg Pak. 2010;20(1):3-5.

12. Fellows KE, Smith J, Keanc JF. Preoperative angiocardiography in infants with tetralogy of Fallot. Review of 36 cases. Am J Cardiol. 1981; 47(6): 1279-85.

13. Friedman S, Ash R, Klein D, Johnson J. Anomalous single coronary artery complicating ventriculotomy in a child with cyanotic congenital heart disease. Am Heart J. 1960; 56(1):140-7.

14. Kervancioglu M, Tokel K, Varan B, Yildirim SV. Frequency, origins and courses of anomalous coronary arteries in 607 Turkish children with tetralogy of Fallot. Cardiol J. 2011;18(5):549-51.

15. Dabizzi RP, Teodori G, BaRLETTA ga, Caprioli G, Baldrighi G, Baldrighi V. Associated coronary and cardiac anomalies in the tetralogy of Fallot. An angiographic study. Eur Heart J. 1990;11(8):692-704.

16. Farsani Y. Determination of TOF characteristics in Iranian patients. Iran J Pediatr. 2007;17(1):5-10.

17. Gupta D, Saxena A, Kothari SS, Juneja R, Rajani M, Sharma S, et al. Detection of coronary artery anomalies in tetralogy of Fallot using a specific angiographic protocol. Am J Cardiol. 2001; 87(2):241-4. A9.

18. Hekmat M, Rafieyian S. Foroughi M, Majidi Tehrani MM, Beheshti Monfared M, Hassantash SA. Associated coronary anomalies in 135 Iranian patients with tetralogy of Fallot. Asian Cardiovasc Thorac Ann. 2005;13(4):307-10.

19. Humes RA, Driscoll DJ, Danielson GK, Puga FJ, Tetralogy of Fallot with anomalous origin of left anterior descending coronary artery, Surgical options. J Thorac Cardiovase Surg. 1987;94(5):784-7.

20. Li J.kias ND, Carvalho JS, Ho SY, Coronary arterial anatomy in tetralogy of Fallot: Morphological and clinical correlations. Heart. 1998; 80(2):174-83.

21. Ruzmetov M. Jimenez MA, Pruit A, Turrentine MW, Brown JW. Repair of tetralogy of Fallot with anomalous coronary arteries coursing across the obstructed right ventricular outflow tract. Pediatr Cardiol. 2005; 26(5):537-42. 